\title{
Space and Time: \\ Wind in an Investment Planning Model
}

\author{
Karsten Neuhoff, Andreas Ehrenmann, Lucy \\ Butler, Jim Cust, Harriet Hoexter, Kim Keats, \\ Adam Kreczko, Graham Sinden
}

February 2006

CWPE 0620 and EPRG 0603

These working papers present preliminary research findings, and you are advised to cite with caution unless you first contact the author regarding possible amendments. 


\title{
Space and Time: \\ Wind in an Investment Planning Model
}

\author{
Karsten Neuhoff ${ }^{* 1}$, Andreas Ehrenmann ${ }^{2}$, Lucy Butler ${ }^{3}$, Jim Cust ${ }^{4}$, \\ Harriet Hoexter ${ }^{5}$, Kim Keats ${ }^{6}$, Adam Kreczko ${ }^{7}$, Graham Sinden ${ }^{8}$
}

\begin{abstract}
Investment planning models inform investment decisions and government policies. Current models do not capture the intermittent nature of renewable energy sources, restricting the applicability of the models for high penetrations of renewables. We provide a methodology to capture spatial variation in wind output in combination with transmission constraints. The representation of wind distributions with stochastic approaches or an extensive historic data set would exceed computational constraints for real world application. Hence we restrict the amount of input data, and use boot-strapping to illustrate the robustness of the results. For the UK power system we model wind deployment and the value of transmission capacity.
\end{abstract}

JEL: L94, C61, C53, O21

Keywords: Investment planning model, Wind distribution, Electricity transmission, Renewables

\footnotetext{
Faculty of Economics, University of Cambridge, CB3 9DE, UK, karsten.neuhoff@econ.cam.ac.uk.+44 1223 335290; Fax. +44 1223 335299, (2) Center for operations research and econometrics, Catholic University of Louvain, $(3,4)$ Faculty of Economics, University of Cambridge, $(5,6)$ ICF Consulting, London Office, (7) Science Applications International Corporation (8) Environmental Change Institute, Oxford University. We would like to thank the EPSRC for funding under the SUPERGEN initiative, the Metoffice for data, Dash for free access to the Xpress solver and ICF Consulting for access to the IPM Investment Planning model.
} 


\section{Introduction}

The current debate over energy security and $\mathrm{CO}_{2}$ reduction comprises two distinct dimensions addressing policy objectives and relevant policy prescriptions. First, in the short term, governments aim to increase the contribution of renewable energy sources by single digit percentages numbers. Feed in tariffs and quota systems create competitive markets in which renewable energy technologies can develop and improve their cost competitiveness. Second, in the long-term the governments have committed to reduce $\mathrm{CO}_{2}$ emissions by a multiple of this number, e.g. $60 \%$ in the UK by 2050 , falling within broader efforts towards a climate stabilisation policy.

Various macroeconomic models illustrate pathways from today’s economy towards low carbon futures. They allow us to understand the broad interactions and have been successfully used to inform debates on policy objectives. However, the representation of individual sectors of such models is typically not detailed enough to support the design of specific policy instruments or facilitate investment decisions of private entities. As a consequence, in the electric power sector, private sector investment decisions and government policy are informed by power sector specific models called investmentplanning models. They determine the investment and operation pattern to satisfy the predetermined electricity demand while minimising total system costs; these can comprise fuel, maintenance, investment, demand side management and environmental costs. Typically several scenarios are calculated to determine how different evolutions of the electricity system affects the profitability of an investment decisions during the first 15 to 20 years. However, conventional investment-planning models lack the capability to represent the intermittent nature of renewable energy technologies like wind power. This limits the opportunity to run scenarios with high penetration of renewable energy technologies, in both public and private sectors. Although the need for a systems perspective to calculate the value of wind power has been recognised (e.g. Kahn, 2004) few attempts have yet been made to address this gap in modelling technique.

We develop a methodology to capture the regional variation of wind output for an optimal dispatch algorithm. While the algorithm respects transmission constraints, it does not represent ramping and part load constraints of power stations. The optimal dispatch is used to determine the optimal investment choices. The intermittent nature of wind output is represented as follows: for each model region we collect hourly wind data at various observation points and calculate the power output a generic wind turbine would produce at the observation point. Output is then averaged over all generic turbines in the model region to calculate an hourly load factor for wind turbines. The investment-planning model is 'offered' the option to build turbines in each region with this load factor. As few users would have more than 4GB memory available their computers, we restrict the number of hours for which we represent the wind output. Boot-strapping with different sets of hours shows that the results are only marginally affected by this limitation. 
In our model of the economics of wind integration we ignore many aspects that affect both the economics and security. While the simplification facilitates interpretation of the results, we suggest that further research addresses the following issues. Wind turbines are connected to the power grid using power electronics; both the design and operation of which currently imply that wind turbines provide less support to ride the system through a short circuit, yet we expect that power electronics will improve or that conventional generators are retained spinning to provide the short circuit ride through. Similarly inertia to provide primary responses is currently only offered to a limited extent by wind turbines, but if either power electronics are built larger or can be operated for fractions of a second above their normal operation point, then the inertia from the rotor could provide spinning reserve. The regional diversification of wind generators implies that the volatility of their joint output is smoothed out; therefore on-shore wind is not expected to create additional system requirements to cope with short-term volatility. There is some discussion to what extent off-shore wind farms with several GW capacity would provide output from turbines that is highly correlated and thus would create power swings that exceed the swings that would result from the failure of a $1 \mathrm{GW}$ nuclear power station. In this case additional costs would be incurred to provide the required inertia and spinning reserve. In terms of the system operation, we do not model how much capacity has to be retained at part load levels on the system to provide sufficient secondary reserve and the resulting decrease in energy efficiency and increase SOx and NOx emissions at such part load operation of Combined Cycle Gas Turbines (CCs) and Coal power stations outside of their optimal generation point. A model incorporating ramping constraints and part load and start up costs will attribute higher value to open cycle gas turbines relative to combined cycle gas turbines than observed in the model presented in this paper. This might imply some of the investment suggested for CCs flows towards open cycle gas turbines.

\section{Literature Review}

The modelling of optimal investment in new energy generation was first attempted in France during the 1950's. Bessiere (1970) describes the “Investment 85” model used by EdF and also gives an overview of previous work that the model draws upon. The "Investment 85" model already contained many key features of the current investment planning models, despite its relatively small size (the original problem had only 159 variables). "Investment 85 ” is a convex cost minimization model that distinguished between investment and operational decisions. It allows for investment in different types of generation in different zones and contain cost of failure terms in the objective function. Uncertainties are expressed either by expected values or by 'safety margins'.

More sophisticated modelling of plant unavailability started around the same time with Baleriaux et al. (1967) and Booth (1972). They introduced a probabilistic simulation that made the calculation of expected unserved energy possible. Blooms (1983) reformulation allowed the use of a Generalized benders decomposition thus allowing for parallel processing to be able to calculate the solutions for bigger problems. These probabilistic simulations have then been used by numerous authors to deter- 
mine an economic argument for the level of reserve capacity (Telson 1975; Munasinghe, Scott et al. 1979).

In the recent literature, DeCarolis and Keith (forthcoming) use five years of hourly demand and wind production pattern to calculate optimal system configuration. The model is however restricted to five production sites, one demand site and only calculates a static long-term equilibrium that does not address the transition from today's energy system.

All this literature focuses on an energy system with a central planner. The only type of uncertainty that has been discussed for non-regulated markets is uncertainty of demand, starting with Gabsezewicz and Poddar (1997) in which the case of a duopoly of generators with investment decisions in two stages is discussed. More recently Murphy and Smeers (2002) compare investment decisions of one and two stage games under uncertainty.

The specific focus of this modelling exercise is the cross-correlation of wind. We assess wind speeds in 7 zones. It is well understood that wind speeds in a single location follow a Weibull distribution (http://www.windpower.org/en/tour/wres/weibull.htm). We avoided the technical difficulty to fit a multidimensional Weibull distribution where we could sample wind realizations and directly use historical data. With a bootstrapping approach we then test the robustness of the results to the limited set of input data.

Early research in power markets usually disregarded transmission constraints or considered only Kirchhoff's current law, disregarding the voltage law that forces power to flow in parallel paths. However, because the voltage law results in tighter constraints in flows and can yield unexpected prices, more recent transmission-constrained models have included both of Kirchhoff's laws. ${ }^{1}$ This is usually accomplished using the linearized "DC" load flow model (Schweppe, Caramanis et al. 1988), in which constant "power transmission distribution factors" $P T D F_{i j k}$ describe how many MW of flow occur on a particular line $k$ in response to an assumed injection of $1 \mathrm{MW}$ at node (or "bus") $i$ and a matching withdrawal of MW at bus $j$. The DC model's linearity allows the use of the principle of superposition, which simplifies load flow calculations for market models relative to the complete nonlinear AC load flow model. The DC model disregards reactive power flows and voltage constraints, and usually excludes calculations of resistance losses.

\footnotetext{
${ }^{1}$ As an example of the counterintuitive effects of Kirchhoff's Voltage Law, an addition of a transmission line can lower the transmission capacity of a system (Wu et al., 1996) an optimal strategy of a Cournot generator can be to increase output in order to congest lines and keep out competition (Cardell et al., 1997); and decreased market concentration can increase prices by worsening transmission congestion at critical locations (Berry et al., 1999; Hobbs et al., 2004).
} 


\section{Investment Planning Model}

For our analysis, we use a customised version of the investment planning model developed by ICF Consulting. The Integrated Planning Model (IPM® ${ }^{\circledR}$ ) uses a linear programming formulation to select investment options and to dispatch generating and load management resources to meet overall electric demand today and on an ongoing basis over the chosen planning horizon. The Xpress linear programme solver from Dash was used to find the optimal solution of that problem. Further details about the model are available from the EPA website (http://www.epa.gov/airmarkets/epa-ipm/). The basic formulation of an investment planning problem is introduced by Bessiere (1970), and here we provide a brief illustration.

System dispatch is optimised given the assumptions on security requirements, fuel and other costs including environmental costs, and transmission possibilities. The resulting solution minimises the present value of total production and investment costs for any set of constraints defined. Figure 1 illustrates how this involves determining for every time-period, or in our case five-year period, how much investment of different technologies will occur in different regions. Given the stock of existing capacity and the new investment the model then solves for the cheapest way to dispatch the system to satisfy demand. This could also involve demand side response, which we currently model to be available at 1000 Euro/MWh. Transmission capacity between different regions is exogenously defined and the model determines how best to make use of the capacity to minimise system costs. Dispatch of pondage and pump storage is determined endogenously such that energy budgets are satisfied on a weekly basis.

We impose a finite horizon, hence it is necessary to ensure that this does not create distortions to the model results. If we were to add the total investment costs of a power plant to the system costs, then this would create distortions, as benefits offered outside the model time frame are not represented. Hence only the capital cost (interest and depreciation) of power stations are attributed to any period.

The European Emission Trading System requires power stations to present $\mathrm{CO}_{2}$ allowances for each tonne of $\mathrm{CO}_{2}$ they are emitting. While power stations are allocated most of the allowances for free, they have the opportunity to sell allowances. Hence we include the full (opportunity) costs of $\mathrm{CO}_{2}$ allowances as variable costs. The price of $\mathrm{CO}_{2}$ allowances is assumed to be exogenous, which can be justified for example by the size of the UK being small relative to the European Emission Trading scheme (Keats and Neuhoff (2004) for further discussion). 


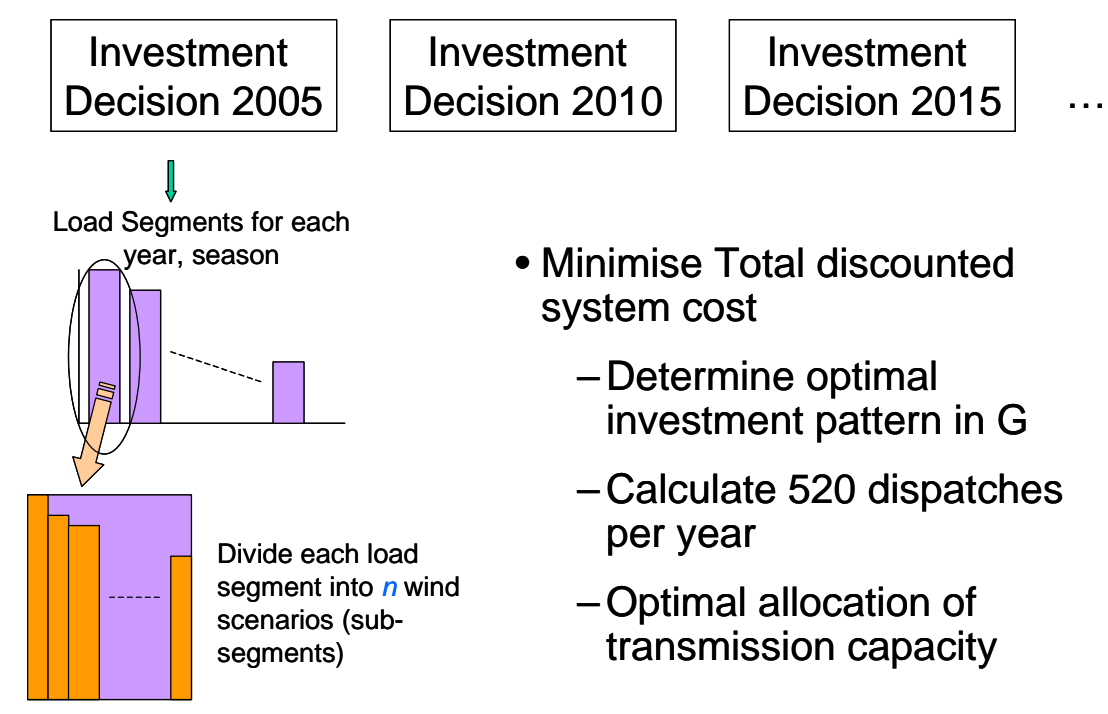

Figure 1 - Investment Decision Mechanism

The novel component in our analysis is the representation of the spatial and time characteristics of wind power within the framework of an investment-planning model. After extensive tests of the data and experimenting with various approaches, the following method provided robust results. We first split the year into 52 weeks. For each hour of a week we calculate the output of a standard wind turbine using historic data for that week. Because of computational constraints we then select a weekday, e.g. Monday, and attribute the Monday wind output profile to each day of the week. We also have an hourly demand profile for each of the regions of the entire week. To address computational constraints, we then aggregate the hours of the week into 20 load segments based on the electricity demand. We then calculate the average wind output for a region and a load segment. This averaging does not distort the calculations of energy values but can impact the value of scarcity prices. Therefore we choose a low resolution during hours of low demand and a high resolution for hours of peak demand. This approach provides us with regional demand and wind output profiles for 20 load segments for 52 weeks. It also leaves wind data for six other weekdays to test how robust the results are to the specific realisation of the wind output - boot strapping.

\section{Test System}

In this section we describe the wind data and the assumptions on existing and potential new power stations used in the model.

\subsection{Wind data}

Observed hourly wind speed measurements recorded at 24 sites in the UK for 1995 have been used to model wind power output from a hypothetical array of wind turbines located in all regions of the UK (Figure 2). The UK Met Office operated all wind speed-recording sites, and the wind speed data were 
obtained from the UK Met Office and British Atmospheric Data Centre. Observed wind speed data allows the representation of patterns of wind availability in areas of GB where wind turbines have yet to be developed.

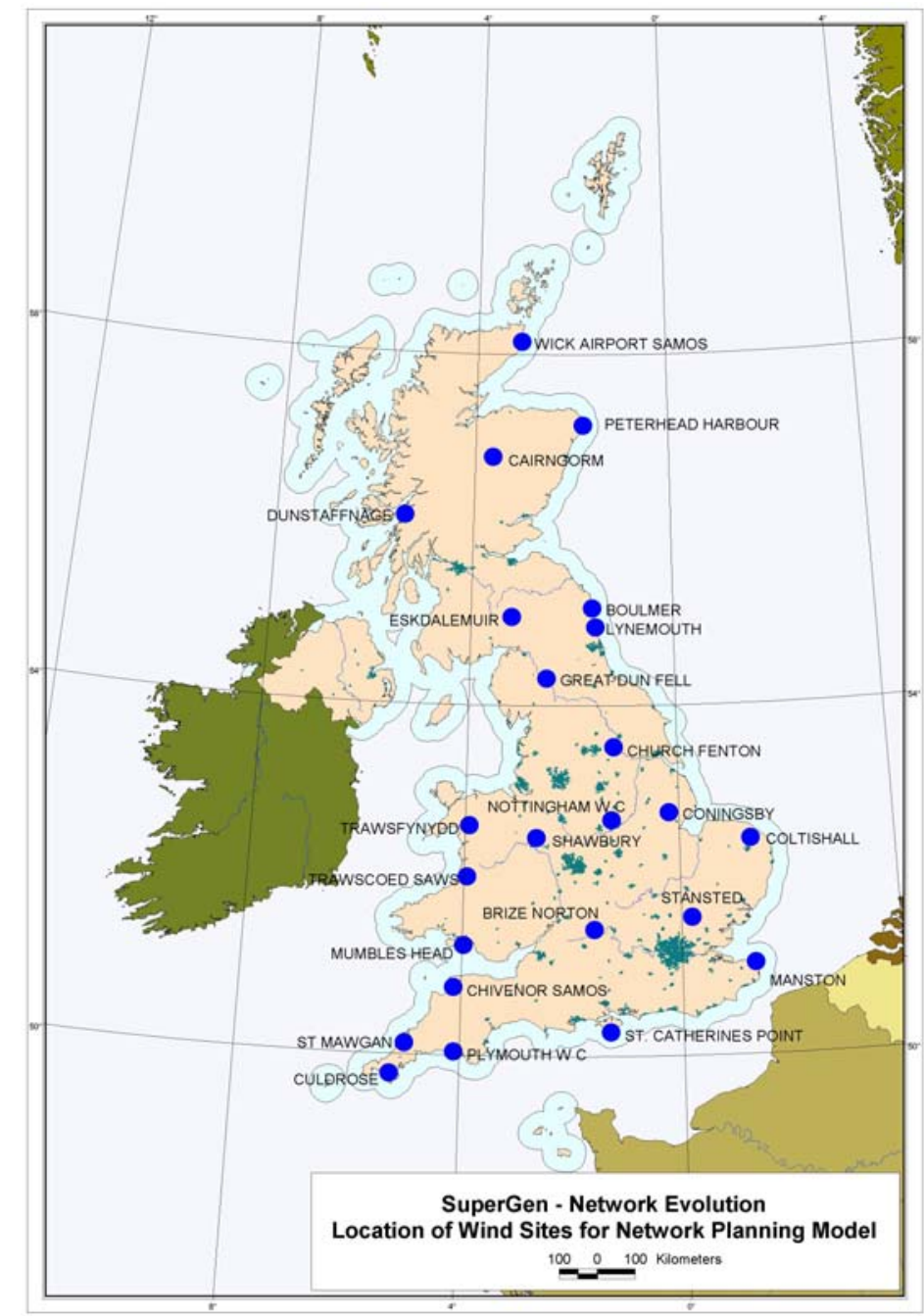

Figure 2 - Site Location

As the wind speed data is collected at the land surface, the reported data were corrected for the increased wind speed that would be encountered at turbine hub height. The corrected hourly wind speed data were converted into power output using published power transform data for a Nordex N80 wind turbine (Nordex 2004). This turbine has a cut-in speed of $4 \mathrm{~ms}^{-1}$, will cease operating in wind speeds over $25 \mathrm{~ms}^{-1}$, and has a rated power output of $2.5 \mathrm{MW}$. We take the average calculated power output on all wind measurement stations in each region as the power output in this region for a new build station for each hour.

The following table illustrates that average wind outputs vary significantly between the regions.

While a 1 MW wind turbine in Scotland can be expected to produce 3425 MWh per year the same turbine located in the midlands only produced 1673 MWh. 


\begin{tabular}{|c|c|c|c|c|c|c|c|}
\hline & $\mathrm{SCO}$ & UNO & NOR & MID & CEN & SWE & EST \\
\hline Full Load Hours & 3425 & 2454 & 2932 & 1673 & 2512 & 3335 & 2525 \\
\hline
\end{tabular}

Table 1 - Wind full load hours by region

\subsection{Transmission Network}

We use the representation of the UK transmission network as proposed by Transco Plc in the sevenyear statement. As illustrated in Figure 3 the transmission regions are defined such that only a unique path way is available for any transmission between two regions. Hence for this specific application even a contract path implementation would have been possible. In reality the transmission network is more complex, and loop-flows create interactions between various transmission pathways. Whilst attracted by the idea of a more accurate representation of the transmission network, a reliable definition of all contingency constraints is yet to be found in the model with a lower level of aggregation.

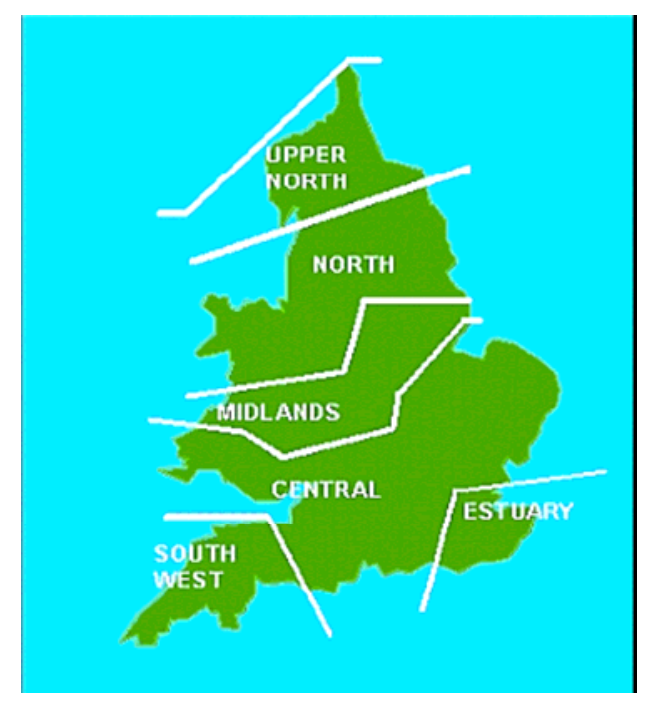

Figure 3 Model Regions

\subsection{Power stations}

For existing power stations we used the database developed by ICF consulting. Here, the retirement of power plants is determined exogenously, for example it is assumed that nuclear power stations retire as anticipated in the seven-year statement of the UK transmission owner and operator NGT (http://www.nationalgrid.com). For coal-powered plants, the large combustion plant directive requires upgrading of existing coal stations. We also use separate model runs by ICF, which indicate that a large amount of coal power stations could be shut down by 2016. While this represents only one scenario run of their simulation, it has the advantage that it allows the model to replace these power stations with other alternatives. 
The model encorporates three options to build new power stations. First, as base load power stations, combined cycle gas turbines are widely expected to dominate the picture and are therefore the suggested option. Secondly, for investment in peaking capacity, open cycle gas turbines are modelled as they offer the cheapest capital costs. Thirdly, for investment in wind turbines, we do not differentiate between on and off-shore turbines, but assume a homogeneous price for any technology at any location. Locations are only differentiated by different availability of wind and their transmission links to other regions. We determined the capital costs of wind turbines to achieve our target wind penetration of $40 \%$ by 2020 . We initially envisaged implementing capital costs of wind turbines below current market prices of around 800-1090Euro/KW (IEA 2005). This difference could have been explained by wind power support mechanisms. However, as Table 2 illustrates, it is necessary to implement capital costs for wind turbines that significantly exceed current market prices. We exclude any income derived from the Renewables Obligation and the lifespan of the wind turbines is assumed to be 25 years.

\begin{tabular}{|llll|}
\hline & \multicolumn{3}{c|}{ Investment Cost $€ / \mathrm{KW}$} \\
& CC (11\%) & Wind (11\%) & CT (11\%) \\
2005 & 580 & 1250 & 370 \\
2010 & 550 & 1160 & 350 \\
2015 & 520 & 1075 & 330 \\
2020 & 500 & 920 & 320 \\
\hline
\end{tabular}

Table 2 Capital costs and discount rates used

While the current combination of gas, coal and $\mathrm{CO}_{2}$ prices does suggest some potential for new coal power stations, we assumed that environmental permitting might be challenging and their large-scale application would preclude compliance with Kyoto objectives. Therefore we did not model new build coal power stations.

Table 3 lists our fuel price assumptions. Each model year represents five real years, hence we do not take the currently (2005) extremely high gas prices as basis for the calculations of 2005, but assume persistently high gas prices. Coal price predictions are somewhat more robust, as the larger basis of suppliers and established bulk transport in ships should create less mid-term price uncertainty.

The big question relates to the $\mathrm{CO}_{2}$ allowance prices. Once again we take a somewhat conservative approach and set prices below the currently observed market prices. This might also correct for some 
of the distortions between market prices and opportunity costs of emitting $\mathrm{CO}_{2}$ that are created in the EU ETS National Allocation Plans.

\begin{tabular}{|c|c|c|c|c|c|c|c|}
\hline & Fuel Costs & & & Typ & margi & nerati & osts \\
\hline & $\mathrm{CC}$ & Coal & $\mathrm{CO} 2$ & $\mathrm{CC} €$ & & Coal & Vhe \\
\hline & $(€ / \mathrm{mmbtu})$ & $€ /$ ton & prices & & $\mathrm{CO}_{2}$ & Fuel & $\mathrm{CO}_{2}$ \\
\hline & & & $(€)$ & Fuel & & & \\
\hline 2005 & 4.43 & 63.36 & 10 & 30.2 & 4 & 26 & 9 \\
\hline 2010 & 4.20 & 31.61 & 20 & 28.7 & 8 & 13 & 18 \\
\hline 2015 & 3.91 & 31.61 & 20 & 26.7 & 8 & 13 & 18 \\
\hline 2020 & 3.90 & 31.61 & 20 & 26.6 & 8 & 13 & 18 \\
\hline
\end{tabular}

Table 3 - Coal, gas price and $\mathrm{CO}_{2}$ price assumptions

\subsection{Demand}

We use hourly demand data for England and Scotland and allocate it to the individual zones proportional to the demand levels reported in the seven-year statement.

\section{Model Results}

In our base case we assume the current transmission capacity and demand, generation and wind data as described in the previous section. The model then calculates the forward looking least cost investment and operation plan to serve demand. Figure 4 illustrates the resulting cumulative new build in each of the regions. 


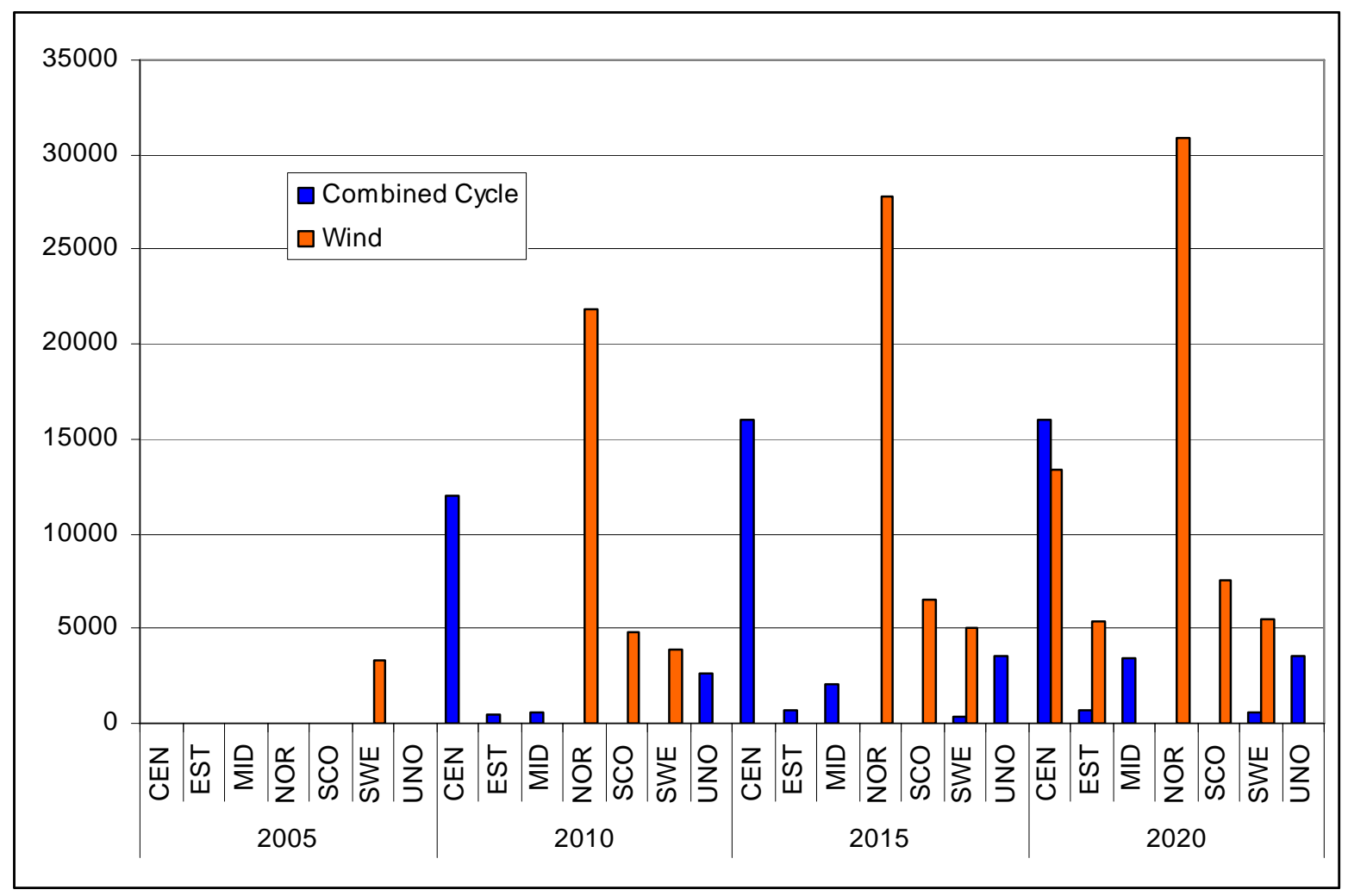

Figure 4 Cumulative Capacity Additions (MW), base case

In the initial period, aggregating the years 2005-2009, all new wind turbines are built in the South West, including Cornwall. The combination of high wind speeds and good availability of transmission capacity links to the region results in a comparative advantage over Scotland where transmission constraints southwards reduce the value of wind output. This is also reflected in the wind investment in 2010 - where despite the higher wind speeds in Scotland the better location on the National Transmission System imply higher build rates in the North of England. In our baseline scenario we do not model the siting constraints or costs of connecting to the distribution network within regions. Therefore regional build rates might exceed levels that would be judged plausible based on these constraints.

The high build rate for combined cycle gas turbines, starting in 2010, is mainly driven by the high $\mathrm{CO}_{2}$ prices, which result in a shift of electricity production from coal to gas. But their construction is also viable because starting in 2016, large amounts of old coal fired power stations are shut down as response to the Large Combustion Plant directive. Finally we note that despite the availability of a low cost option to provide peaking capacity, no open cycle gas turbines are built in this scenario. 
Figure 5 illustrates how the share of different fuels serving the energy demand evolves over time. ${ }^{2}$

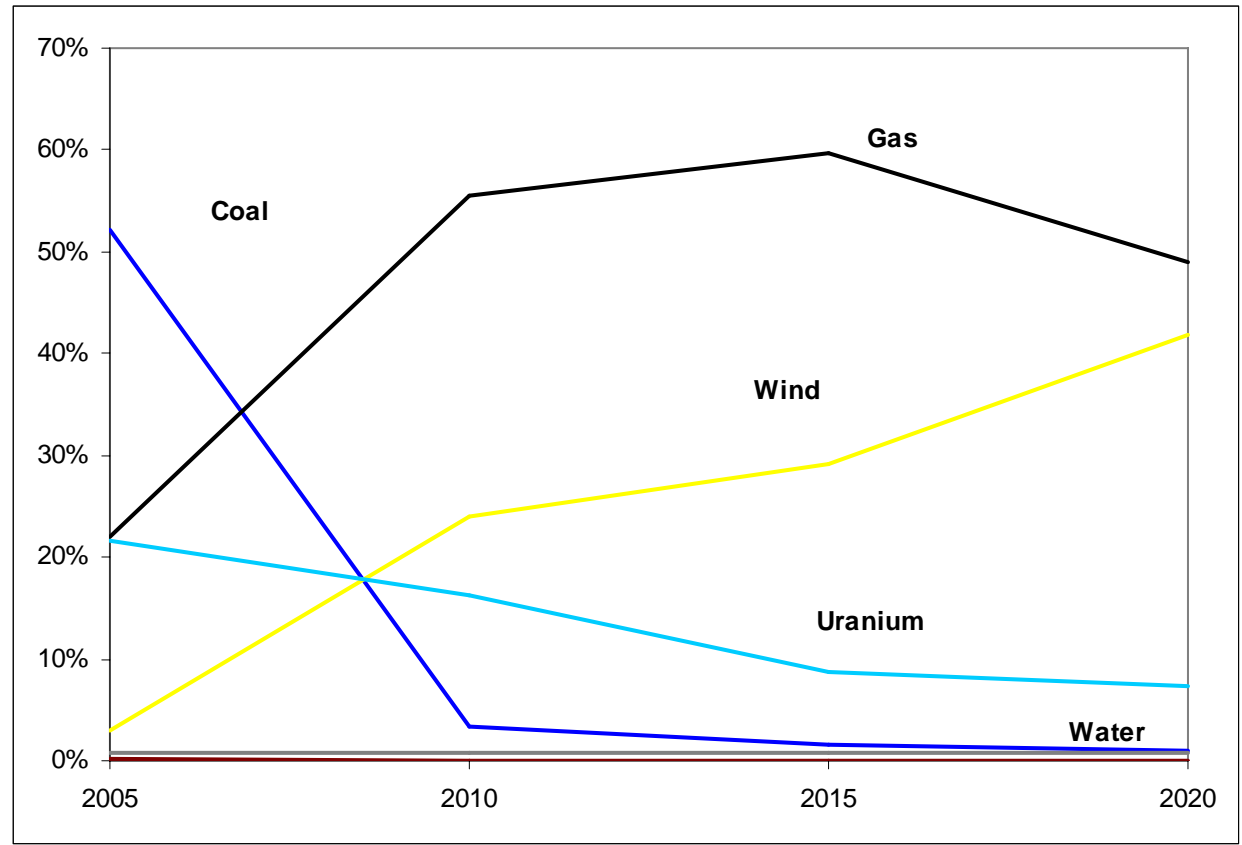

Figure 5 Evolution of share of energy sources

Figure 6 illustrates the impact of transmission constraints within our system. In the absence of the constraints the amount of installed wind capacity would slightly increase, but it would be shifted from regions with good transmission interconnection - e.g. North and Central - towards locations with higher wind speeds, especially Scotland and the South West. The main insight from this comparison is that an accurate model representation needs to capture transmission constraints of a power system.

\footnotetext{
${ }^{2}$ The share of coal declines rapidly which is likely to be partially induced by our assumption of a exogenously fixed $\mathrm{CO}_{2}$ price. Whilst the $\mathrm{CO}_{2}$ price can be said to be exogenously determined for the $\mathrm{UK}$, should such a $\mathrm{CO}_{2}$ price prompt similar shifts away from coal across Europe, it is likely some fall in the $\mathrm{CO}_{2}$ allowance price may also be observed. As a consequence such a drop in coal usage is likely to be delayed in the UK.
} 


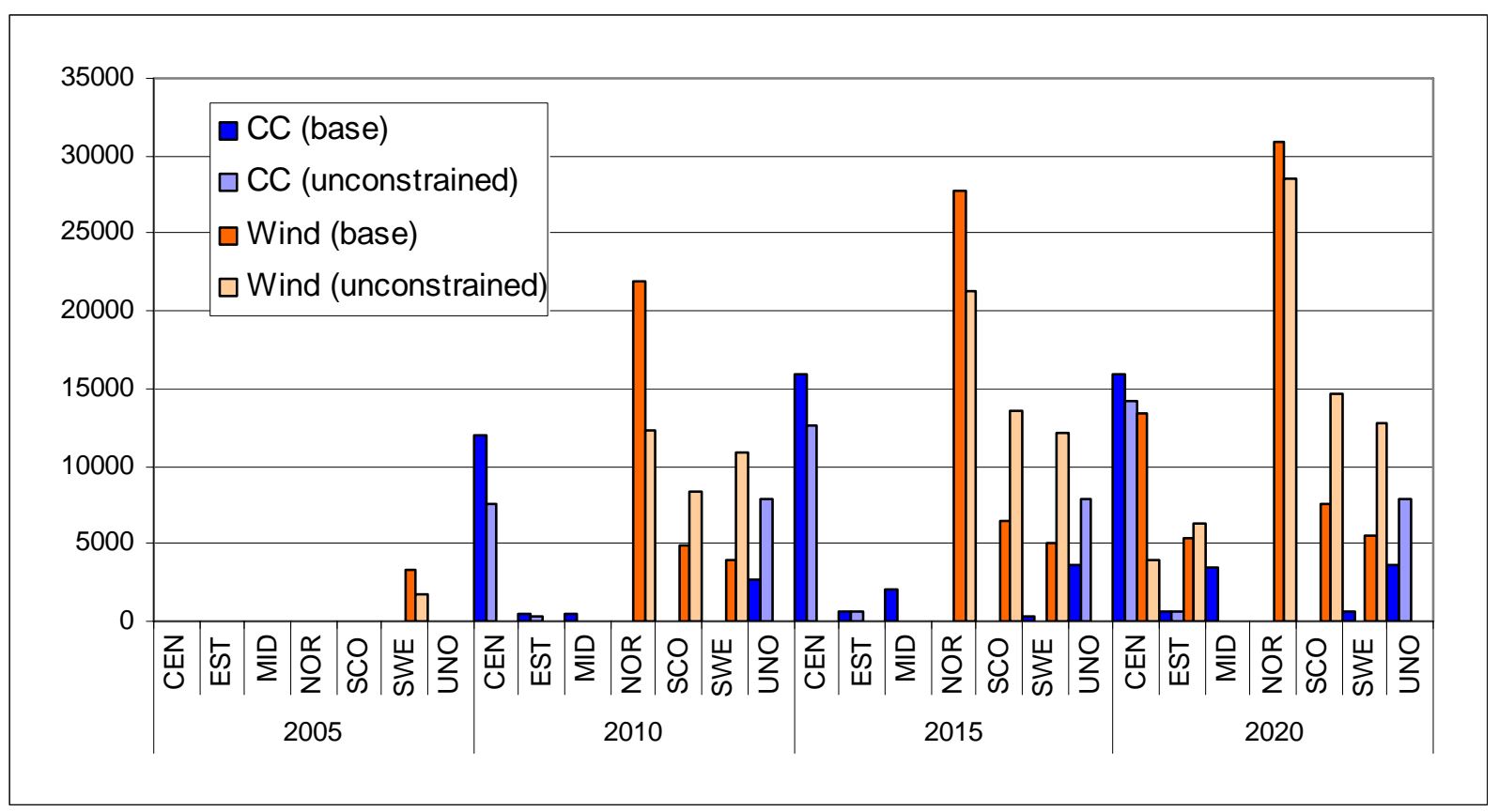

Figure 6 Cumulative build for base case without transmission constraints

Siting constraints for wind turbines are likely to create limits to the maximum build per region. We impose restrictions on new wind investment to $2.5 \mathrm{GW}$ per region and five-year period. We do not impose such constraints on Scotland. We also reduced the price of wind turbines by 20\% (down to 1000 Euro/kW in 2005) thus inducing an investment in wind energy that supplies the same amount of total energy from wind as in the previous scenario. The deployment limit is binding in regions Central, Estuary and North throughout the period and in the South-West for the first five year period. Figure 7 illustrates shifts of wind investment from the North. We see some additional wind in regions Estuary, Scotland South-West and Upper-North across the period, but either transmission constraints, build constraints or both are seen to be binding. 


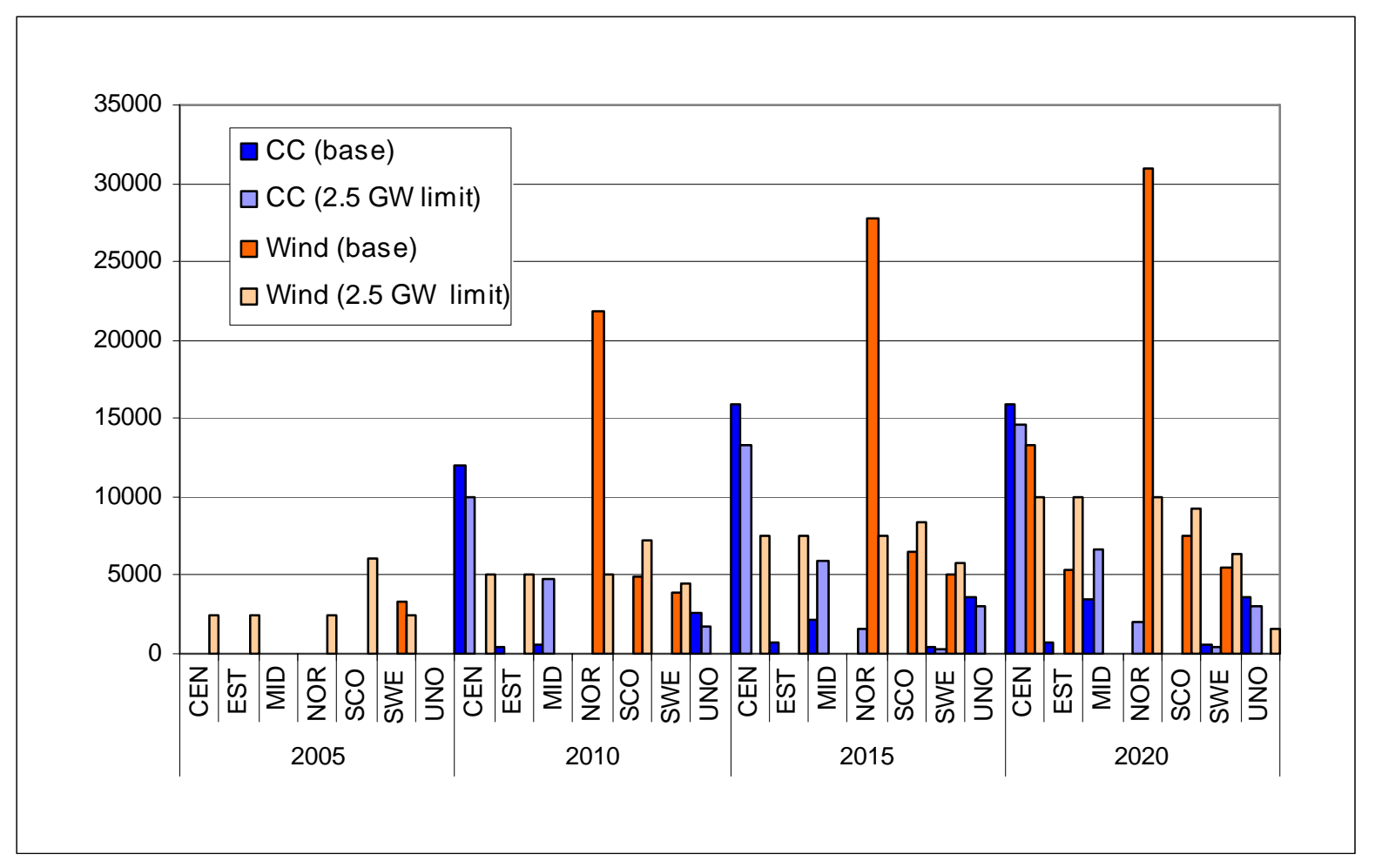

Figure 7 - Effect of transmission constraints and 2.5 GW / 5 year interval max build per region (other than Scotland) (new wind price scenario)

In contrast to many current expectations of very high usage of the good Scottish wind resources, in our model only $17 \%$ of wind power is deployed there. Hence we increase the transmission capacity on the interconnection from Scotland via Upper North, North, Midlands to Central by 1 GW.

Figure 8 shows that the increased transmission capacity allows for better use of the Scottish wind resource and deployment of additional wind turbines. Although we had expected that the Scottish wind turbines would replace turbines in other regions, the simulation of the optimal investment path did not confirm this expectation. Clearly, if renewable quotas would determine the total investment quantity rather than the investment within a competitive market, then such replacement would be observed. The additional transmission capacity allows the relocation and reduction of investment in combined cycle gas turbines. 


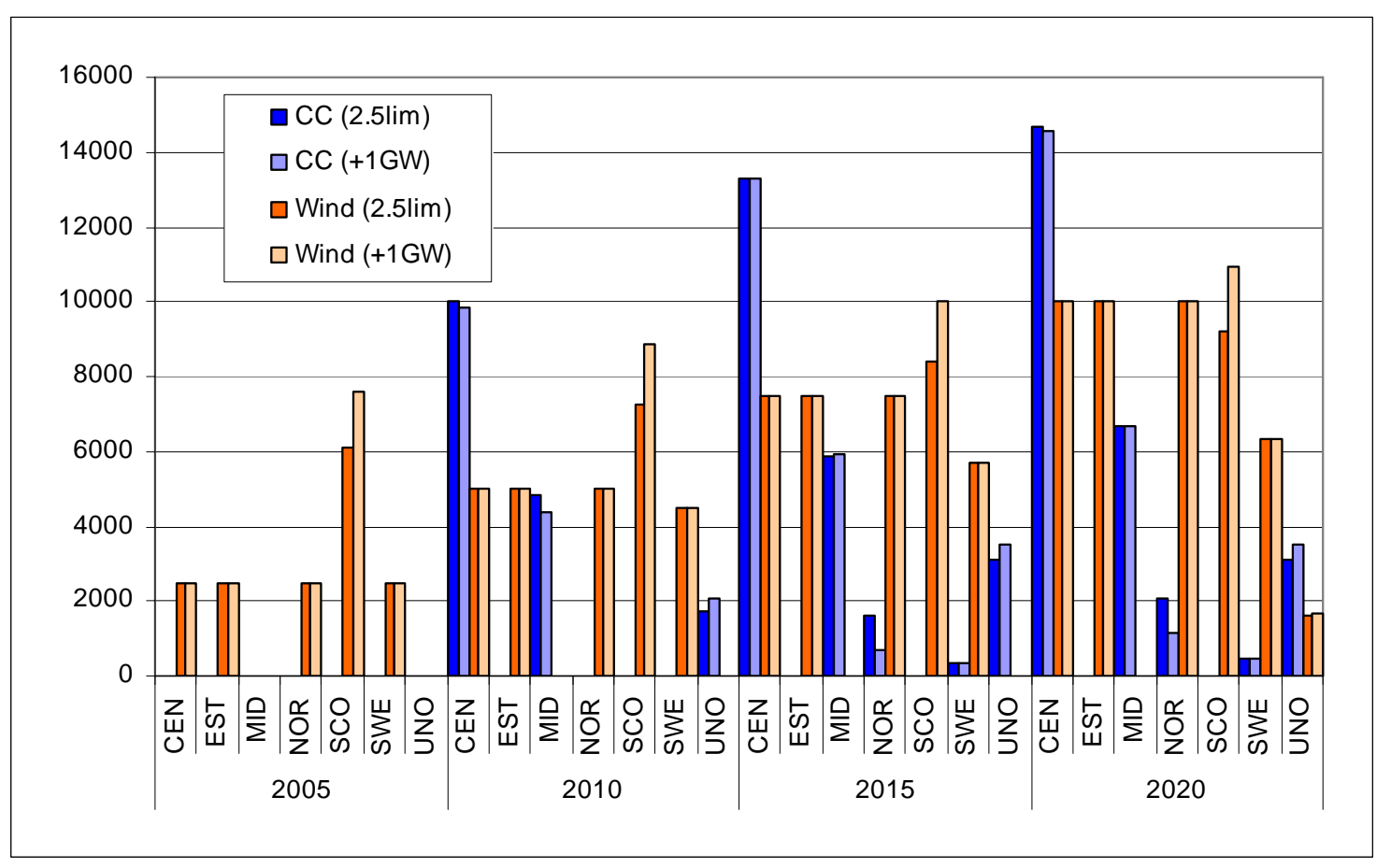

Figure 8 - Effect of +1GW transmission to SCO (with wind build limit)

Table 4 shows the cost savings that could be achieved in an optimal system if 1GW extra transmission capacity would be available. The new system exhibits lower fuel and CO2 costs as wind power replaces conventional generation. However, the fuel savings are partially compensated for by additional capital costs for the financing of additional wind turbines. The net effect is an average saving of 25 million Euro (€5m per yr). This is not exuberant relative to the investment costs of several hundred million Euro that could be expected for such an interconnection.

\begin{tabular}{|l|l|l|l|l|}
\hline & $\mathbf{2 0 0 5}$ & $\mathbf{2 0 1 0}$ & $\mathbf{2 0 1 5}$ & $\mathbf{2 0 2 0}$ \\
\hline Variable costs & -9.1 & -3.3 & 0.5 & 0 \\
\hline Fuel cost & -146.1 & -132 & -128.3 & -148.9 \\
\hline $\begin{array}{l}\text { Capital repayments for } \\
\text { simulated new build }\end{array}$ & 168.5 & 158.6 & 145.8 & 157.5 \\
\hline $\begin{array}{l}\mathrm{CO}_{2} \text { emissions valued } \\
\text { at 20Euro/t }\end{array}$ & -37.6 & -49.7 & -41.8 & -44.8 \\
\hline Total & $\mathbf{- 2 4 . 3}$ & $\mathbf{- 2 6 . 4}$ & $\mathbf{- 2 4 . 0}$ & $\mathbf{- 3 6 . 2}$ \\
\hline
\end{tabular}

Table 4 Changes of annual costs (in $€ \mathrm{~m}$ ) if transmission capacity to Scotland were $1 \mathrm{GW}$ bigger. (excluding costs of extra transmission lines) 
Finally, Figure 9 illustrates the impact of the $\mathrm{CO}_{2}$ allowance prices in the baseline scenario. Without the allowance price new build of Combined Cycle gas turbines is reduced, as coal power stations are operated at higher rates. The lower costs of producing electricity with conventional fuels all but inhibit the use of wind power. The lower investment in wind power implies that instead of $40 \%$ energy produced by wind power in 2020 we only observe $6 \%$. The sensitivity of wind investment to the $\mathrm{CO}_{2}$ price illustrates the investment risk in power generation, and particularly in renewable energy sources.

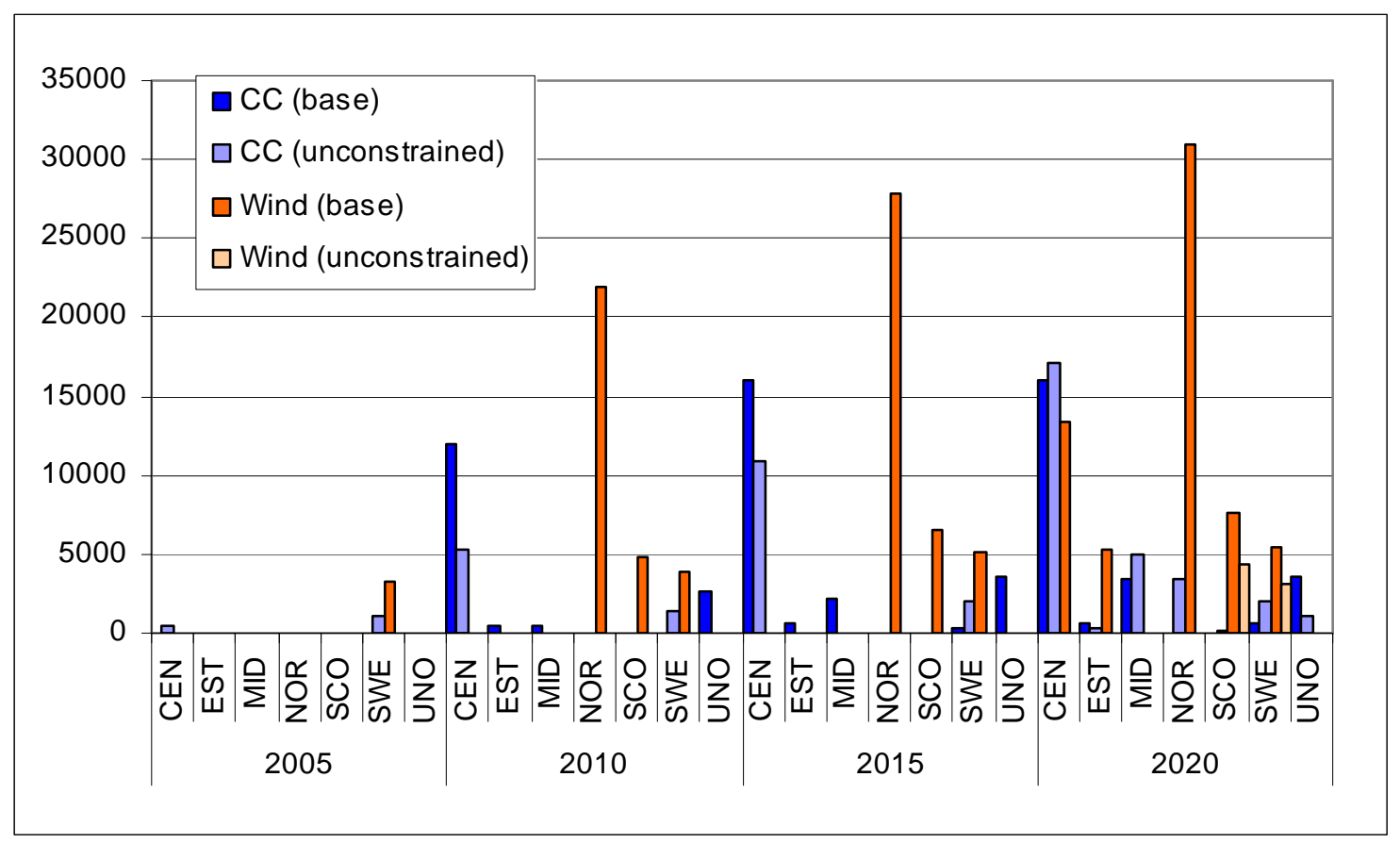

Figure 9 Capacity expansion without $\mathrm{CO}$ constraint

\section{Robustness Test}

The model run is limited to 1120 dispatch scenarios per model year. Scenarios must capture volatility in demand and volatility in wind availability in different regions. Hence only a small subset of the space of total realisations can be sampled. Of particular concern when using our methodology is how the choice of the subset would affect the results. Hence a bootstrap type approach is used to measure the sensitivity of the model results to the wind data by running the model separately with wind data collected for a different weekday. We normalised the wind output for a weekday in each region to the average annual wind output using a linear scaling. This does not affect the regional interactions in which we are interested. 
Figure 10 illustrates the UK wide cumulative installed wind capacity that is modelled using wind data for different weekdays. It indicates the extent to which the results are robust to the choice of the weekday.

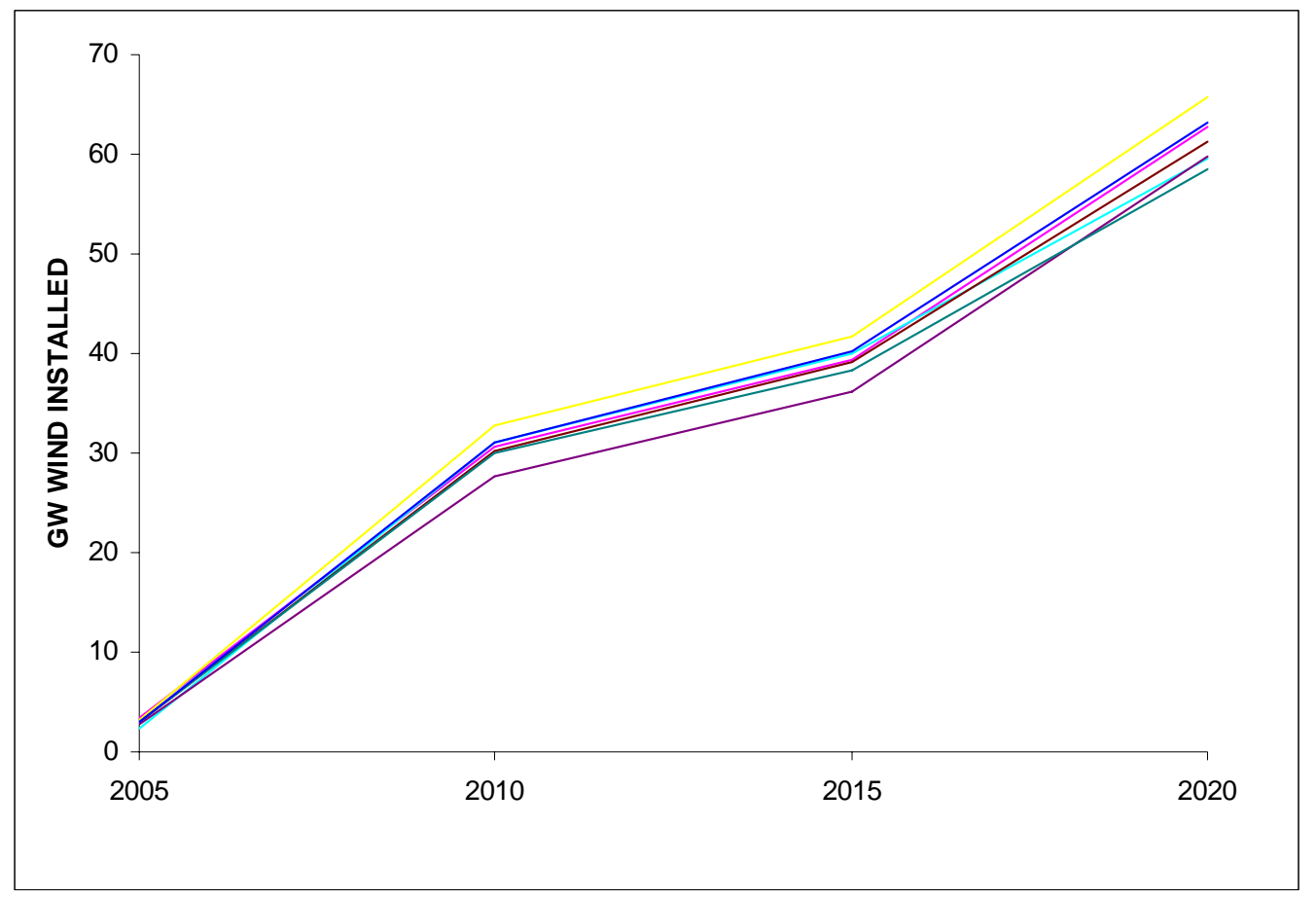

Figure 10 Robustness measure, global installed wind capacity for different wind data, by region.

Also of interest is the extent to which the spatial pattern we observe in our model results is robust towards our random choice of the weekday for wind input data. The first row in Table 5 illustrates that range of volatility of the regional shares of wind build. In region Estuary the wind build varies significantly with the choice of the weekday for the wind input data. If the installed capacity in Estuary is assessed jointly with Central, then the variance is reduced. This indicates that the allocation of wind turbines between two neighbouring regions with little transmission constraints and similar wind pattern can drastically change with small changes of the wind input data - a switching phenomena that is frequently observed in optimisation models.

\begin{tabular}{|c|c|c|c|c|c|c|c|c|}
\hline Wind by 2020 & CEN & EST & CEN\&EST MID & & NOR & $\mathrm{SCO}$ & SWE & UNO \\
\hline ST D Reg/ Avg Total & $3.65 \%$ & $2.87 \%$ & $3.99 \%$ & 0 & $2.51 \%$ & $0.48 \%$ & $0.41 \%$ & 0 \\
\hline ST D Reg/ Avg Reg & $16.89 \%$ & $49.08 \%$ & $14.51 \%$ & - & $4.79 \%$ & $4.16 \%$ & $4.81 \%$ & - \\
\hline Region/Total Build & $22 \%$ & $6 \%$ & $27 \%$ & 0 & $52 \%$ & $12 \%$ & $9 \%$ & 0 \\
\hline
\end{tabular}

Table 5 Wind build, sensitivity of regional patterns to choice of wind input data

A second parameter of significance in our model approach is the temporal resolution of the model. The model uses the hourly demand input data for each hour of the week. These $7 * 24$ hours must then be aggregated into 20 demand slots. As the high demand realisations are particular relevant for the 
investment requirement, we choose a high resolution for these realisations and only a broad resolution of the remaining demand realisations. Table 6 illustrates the grouping of hours in our representation.

\begin{tabular}{|l|lllllllllllllllllllll|}
\hline Demand & 1 & 2 & 3 & 4 & 5 & 6 & 7 & 8 & 9 & 10 & 11 & 12 & 13 & 14 & 15 & 16 & 17 & 18 & 19 & 20 \\
\hline $\begin{array}{l}\text { Number } \\
\text { of Hours }\end{array}$ & 1 & 1 & 1 & 2 & 2 & 7 & 11 & 9 & 8 & 8 & 9 & 8 & 9 & 16 & 17 & 17 & 8 & 9 & 8 & 17 \\
\hline
\end{tabular}

Table 6 - Demand Hours sorted by slot: high to low

After the hours in the wind representation are grouped into these demand groups, the regional wind output for each group has to be determined by averaging over the wind output of all hours in the group. The wind representation of the peak demand realisation is therefore accurate, whereas the representation of the subsequent demand groups is averaged. While Table 6 suggests that most demand groups average over about 8 wind realisations, the real averaging is more limited. This is because the daily load profile exhibits only limited changes between weekdays and therefore the hour 8-9am for most weekdays is part of the same demand group. As we have allocated the same wind realisation to each weekday, the averaging has no effect. However, weekend demand patterns exhibit bigger changes and therefore the aggregation into demand groups does imply some averaging over wind output. Such averaging over wind output smoothes the wind production and therefore increases the value of wind.

To assess the sensitivity of our results to the averaging, we reduce the model resolution to 10 demand groups per week, thus increasing the averaging over wind and demand output. Table 7 illustrates, the higher value of wind due to additional averaging results in additional wind build. Yet the amount of additional build is limited to $4 \%$ and despite the increased averaging over wind output, the amount of peak wind spilled during low demand times in the system increases by $8 \%$. Furthermore, the sensitivity of wind patterns to input wind data is similar under both cases. Hence the test results indicate that additional increases of the resolution as would be required for a more realistic representation of wind patterns have only limited impacts on the final results. Thus our simplified model is able to capture the main characteristics of regional wind patterns.

\begin{tabular}{|c|c|c|c|c|}
\hline & 2020 & Total Costs & Spilled Energy & $\begin{array}{l}\text { Installed Wind } \\
\text { Capacity }\end{array}$ \\
\hline Std Dev 10/ Average 10 & & $0.44 \%$ & $29.32 \%$ & $3.56 \%$ \\
\hline Std Dev 20/ Average 20 & & $0.43 \%$ & $24.69 \%$ & $4.04 \%$ \\
\hline$(A \vee 10-A v 20) / A v 10$ & & $0.28 \%$ & $-7.56 \%$ & $3.06 \%$ \\
\hline
\end{tabular}

Table 7 Sensitivity of results to model resolution - 10 and 20 demand (and wind) realisations per week. 


\section{Conclusion}

We have expanded a traditional investment-planning model to capture the spatial variation and correlation of wind availability in combination with the limitations of interregional exchanges due to transmission constraints. Given computational constraints, the amount of wind input data that can be used for a model run is limited. We therefore use different wind input data to test the robustness of the results, and demonstrate that aggregate figures are robust to such changes. As shown in Table 7, if neighbouring regions only exhibit limited transmission constraints, then significant amounts of the modelled wind deployment can shift between these regions as response to the change of wind input data, suggesting that for such cases, only the aggregate figure for both regions is robust. If the model is run assuming unlimited transmission capacity then the technology choice, investment volume and regional distribution changes significantly. Given the planning difficulties and high costs of transmission expansion, this analysis highlights the importance of transmission constraints in investment pattern modelling.

The model simulates the investment pattern that would be implemented by forward looking, rational and competitive investors. This suggests that the market design should provide these investors with the right price signals indicating the transmission constraints to ensure the optimal technology is build at the optimal location. The current UK paradigm under BETTA hides transmission constraints from operational decisions to support the dogma of bilateral trading independent of centralised transmission allocation. This is likely to result in inefficient investment choices and the regulators' implementation of administrative barriers (connection permission by NGT) and connection charges as function of long-run marginal costs of transmission expansion reflects these concerns. To what extent these instruments accurately represent the impact of very different temporal congestion patterns is, however, outside the scope of this study.

In the model runs, it was necessary to increase the capital costs of wind turbines significantly above current market prices and projected costs in order to limit the deployment of wind power to ensure that only $40 \%$ of UK electricity will be provided by wind power in 2020 . Such higher prices could be interpreted as connection costs within the region where the wind turbines are deployed. The study hence ignores stability requirements (fault ride through), ramping costs and spinning reserve requirements. We hope that our scenarios motivate further engineering studies to assess solutions (e.g. power electronics) to facilitate large-scale use of energy provided by non-synchronised generators. 


\section{References}

Baleriaux, H., E. , F. Jamoulle and L. D. Guertechin (1967). "Simulation de l'exploitation d'un parc de machines thermiques de production d'electricite couple a des stations de Pompage." Revue $E$ edition SRBE(5): 225-245.

Berry, C. A., B. F. Hobbs, W. A. Meroney, R. P. O’Neill and J. W.R. Stewart (1999). "Analyzing Strategic Bidding Behavior in Transmission Networks." Utility Policy 8(3): 139-158.

Bessiere, F. (1970). "The Investment 85 model of Electricite de France." Management Science.

Blooms, J. A. (1983). "Solving an Electricity Generation Planning Problem by Generalized benders De-composition." Operations Research 31(1): 84-100.

Booth, R. R. (1972). "Power System Simulation Model based on Probabilistic Analysis." IEEE Transaction on Power Apparatus Systems PAS-91: 62-69.

Cardell, J., C. C. Hitt and W. W. Hogan (1997). "Market Power and Strategic Interaction in Electricity Networks." Resource and Energy Economics 19(1-2): 109-137.

DeCarolis and Keith (forthcoming). "The Economics of Large-Scale Wind Power in a Carbon Constrained World." Energy Policy.

Gabszewicz, J. J. and S. Poddar (1997). "Demand fluctuations and capacity utilization under duopoly." Economic Theory(10): 131-146.

Hobbs, B. F. and U. Helman (2004). Complementarity-Based Equilibrium Modeling for Electric Power Markets. Modeling Prices in Competitive Electricity Markets. D. Bunn and J. Wiley, in press.

IEA (2005). Projected Costs of Generating Electricity -- 2005 Update, IEA: 232 pages.

Kahn, E. P. (2004). "Effective load carrying capability of wind generation: Initial results with public data." Electricity Journal December: 85-95.

Keats, K. and K. Neuhoff (2004). Allocation of Carbon Emission Certificates in the Power Sector: How Generators Profit from, CMI Working Paper.

Munasinghe, M., W. G. Scott, M. Gellerson and B. World (1979). The economics of power system reliability and planning : theory and case study. Baltimore, Published for the World Bank [by] Johns Hopkins University Press c1979.

Murphy, F. H. and Y. Smeers (2002). "Generation capacity expansion in imperfectly competitive restructured electricity markets." CORE Discussion Paper 2002(69).

Nordex (2004). Nordex data in Wind Power and the UK wind resource, http://www.eci.ox.ac.uk/renewables/UKWind-Report.pdf, Environmental Change Institute

Schweppe, F. C., M. C. Caramanis, R. E. Tabors and R. E. Bohn (1988). "Spot pricing of electricity." Kluwer, Norwell, Massachusetts.

Telson, M. L. (1975). "The Economics of Alternative Levels of Reliability for Electric Power Generation Systems." The Bell Journal of Economics 6(2): 679-694.

Wu, F., V. Pravin, S. T. Pablo and O. Shmuel (1996). "Folk Theorems on Transmission Access: Proofs and Counterexamples." Journal of Regulatory Economics 1996(10): 5-23. 